\title{
Reversible Healing Effect of Water Molecules on Fully Crystallized Metal-Halide Perovskite Film
}

Wenke Zhou, Yicheng Zhao, Chenglong Shi, Haonan Huang, Jing Wei, Rui Fu, Kaihui Liu, Dapeng Yu, Qing Zhao*

State Key Laboratory for Mesoscopic Physics and Electron Microscopy Laboratory, School of Physics, Peking University, Beijing 100871, P. R. China.

Corresponding Author

*E-mail: zhaoqing@pku.edu.cn 


\section{Complete author list of references 2, 8, 9, 14, 15, 17 and 18.}

(2) Kim, H.-S.; Lee, C.-R.; Im, J.-H.; Lee, K.-B.; Moehl, T.; Marchioro, A.; Moon, S.-J.; Humphry-Baker, R.; Yum, J.-H.; Moser, J. E.; Graetzel, M.; Park, N.-G.

(8) Heo, J. H.; Im, S. H.; Noh, J. H.; Mandal, T. N.; Lim, C. S.; Chang, J. A.; Lee, Y.

H.; Kim, H. J.; Sarkar, A.; Nazeeruddin, M. K.; Gratzel, M.; Seok, S. I.

(9) Mei, A. Y.; Li, X.; Liu, L. F.; Ku, Z. L.; Liu, T. F.; Rong, Y. G.; Xu, M.; Hu, M.;

Chen, J. Z.; Yang, Y.; Gratzel, M.; Han, H. W.

(14) You, J. B.; Yang, Y. M.; Hong, Z. R.; Song, T. B.; Meng, L.; Liu, Y. S.; Jiang, C. Y.; Zhou, H. P.; Chang, W. H.; Li, G.; Yang, Y.

(15) Zhang, W.; Saliba, M.; Moore, D. T.; Pathak, S. K.; Horantner, M. T.; Stergiopoulos, T.; Stranks, S. D.; Eperon, G. E.; Alexander-Webber, J. A.; Abate, A.;

Sadhanala, A.; Yao, S. H.; Chen, Y. L.; Friend, R. H.; Estroff, L. A.; Wiesner, U.; Snaith, H. J.

(17) Xu, J.; Buin, A.; Ip, A. H.; Li, W.; Voznyy, O.; Comin, R.; Yuan, M.; Jeon, S.;

Ning, Z.; McDowell, J. J.; Kanjanaboos, P.; Sun, J.-P.; Lan, X.; Quan, L. N.; Kim, D. H.; Hill, I. G.; Maksymovych, P.; Sargent, E. H.

(18) Eperon, G. E.; Habisreutinger, S. N.; Leijtens, T.; Bruijnaers, B. J.; van Franeker, J. J.; dequilettes, D. W.; Pathak, S.; Sutton, R. J.; Grancini, G.; Ginger, D. S.; Janssen, R. A. J.; Petrozza, A.; Snaith, H. J. 


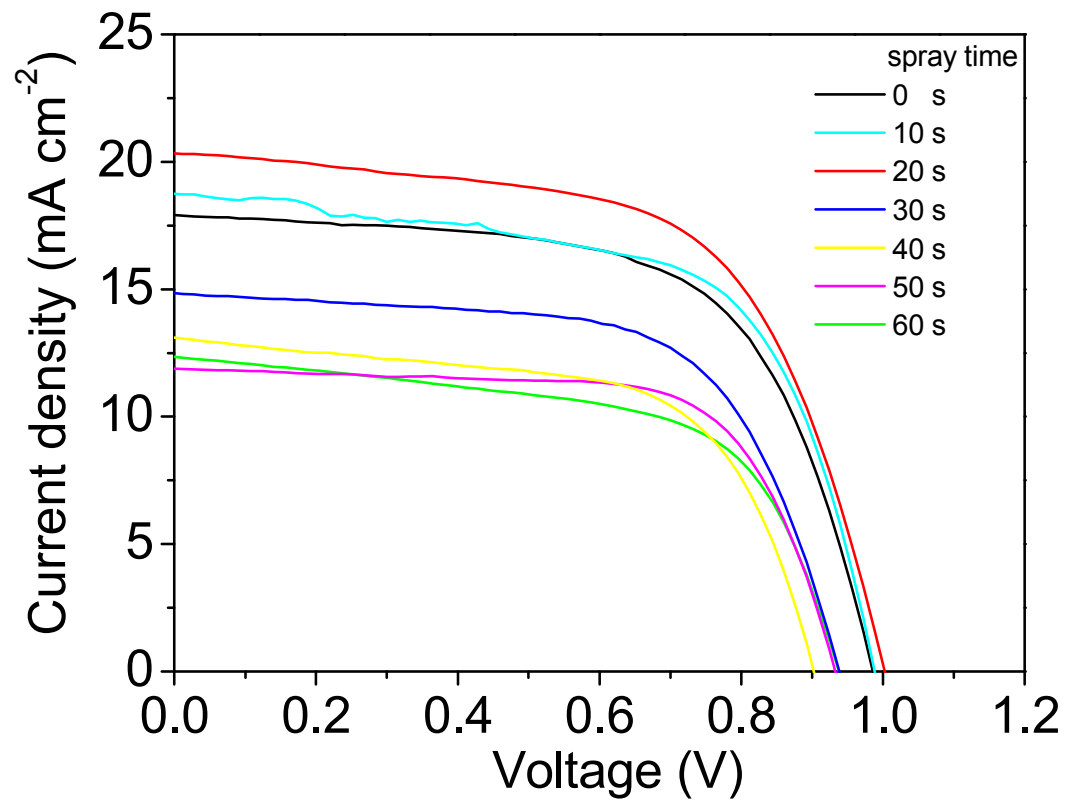

Figure S1. Reverse current-voltage scan for perovskite solar cells made with perovskite films with different vapor spray time. Spraying time of $20 \mathrm{~s}$ is the optimized time which gives the best photovoltaic performance of the corresponding solar cell devices. 
a



b

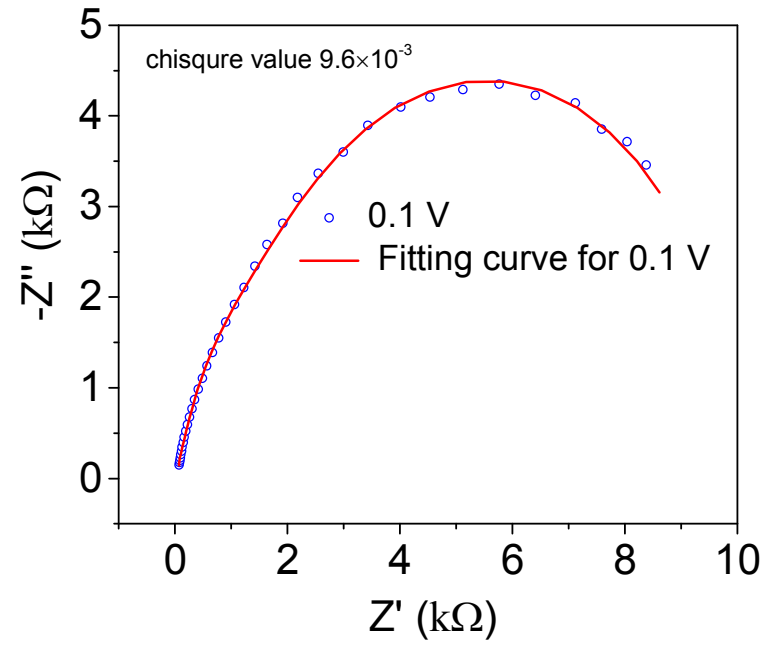

Figure S2. Nyquist plots of device based on perovskite films without spray treatment under $0 \mathrm{~V}$ (a) and $0.1 \mathrm{~V}$ (b). Inset of (a): the equivalent circuit for impedance spectroscopy fitting. The equivalent circuit is based on the work by Shao et al.[1] 

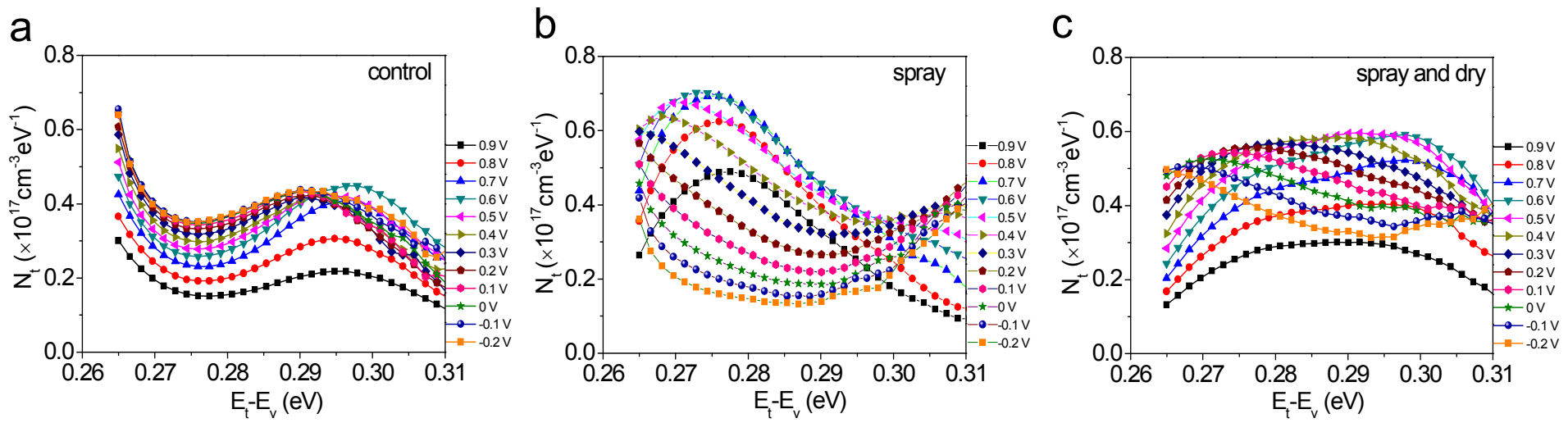

Figure S3. Defect density of states obtained by thermal admittance Spectroscopy for devices made of (a) control (b) sprayed (c) sprayed/dried perovskite films under different applied bias.

\section{REFERENCE}

1. Shao, Y. H.; Xiao, Z. G.; Bi, C.; Yuan, Y. B.; Huang, J. S. Origin and Elimination of Photocurrent Hysteresis by Fullerene Passivation in $\mathrm{CH}_{3} \mathrm{NH}_{3} \mathrm{PbI}_{3}$ Planar Heterojunction Solar Cells. Nat. Commun. 2014, 5, 5784-5790. 